\title{
A NUMERICAL STUDY ON THERMAL STRESS ANALYSIS OF A MICRO ELECTRO MECHANICAL SYSTEMS (MEMS) BIMETALLIC ACTUATOR
}

\section{Dr. CH. SRINIVASA RAO}

Professor, Department of Mechanical Engineering, Kallam Haranadhareddy Institute of Technology,

Chowdavaram, Guntur, Andhra Pradesh, India

\begin{abstract}
Micro Electro Mechanical Systems (MEMS) actuators are capable of obtaining mechanical motion on a very small scale due to the design, materials and fabrication. A bi metallic micro actuator is also one of MEMS device that can perform physical functions at micron meter scale. A bi metallic micro actuator based on thermal sensing is capable of making small displacements due to resultant heating at the end. Because of different thermal expansion coefficients of the bonded strip materials, the actuator undergoes bending and the resultant deformation is a measure of the micro motion. During bending, the stresses generated may cause the beam to undergo staring or deformation. In the present work, MEMS actuator in which a bi metallic strip made up of Silicon dioxide and silicon layers bonded together is modeled and simulated using Finite Element Method for finding the total deformation, stresses and strain. The results are validated with theoretical results and are in good agreement.

KEYWORDS: Micro Electro Mechanical Systems (MEMS), Bimetallic actuator, Thermal stress analysis, Mechanical deformation \& Finite Element Method (FEM)
\end{abstract}

Received: Mar 06, 2020; Accepted: Mar 26, 2020; Published: May 04, 2020; Paper Id.: IJMPERDJUN202029

\section{INTRODUCTION}

Micro Electro Mechanical Systems (MEMS) is a technology of creating materials and devices at the size and scale of 1 to 50 micron meters. It involves fabrication and functionality of various micro sensors and actuators that are used to sense quantities or act in response to changes in that environment. Some of the devices includes transducers, probes, capacitors, inductors, actuatots, gyroscopes, pumps, valves and semiconductor chips. MEMS combine electronics, electrical and mechanical elements for sensing and actuation. Micro sensors and micro actuators are made in silicon materials that are used in Integrated circuit (IC) fabrication. MEMS devices are devices are used in the fields such as aerospace, biomedical, chemical analysis, micro fluidics, optics, etc. [1]. The commonly used sensing and actuating principles are: chemical, optical, thermal, mechanical, piezoresistive, capacitive, piezoelectric, resonant, magnetic, electrostatic, etc [2].

MEMS bimetallic actuators are made with both metallic and non-metallic materials. Thin films with different thermal expansion properties are used to fabricate switches, electrodes, valves, strain gauges, and diaphragms. The operation of the device is affected by the expansion and contraction of the materials at the small scale. Particularly for devices such as micro switches and micro valves, the temperature coefficient of the material is very important to its operation. Thus, the MEMS devices have superior performance with less power consumption when compared to bulk materials with small size, low cost, fast operation, flexibility of design, and easy integration with on-chip electronics [3]. The important feature considered in the design of MEMS is the 
selection of an actuation method. Five major types of actuators are widely used in MEMS. They are electrothermal, electrostatic, piezoelectric, electromagnetic, and Shape Memory Alloy (SMA) based actuators. An actuator is a device that makes the other objects or things to move. A micro actuator accomplishes this through micro actuation. Micro actuators are light weight, comfortable and sophisticated devices. They are used in micro mirrors to scan laser beams, for cutting tools in micro surgery, driving micro pumps and valves for fluid and gas transportation, data reading and recording control, printing applications, optical signal swotching and radi, frequency(RF) signal tuning [4]

Micro actuators are possible due to the development of advanced technologies such as deep X-ray lithography, LIGA (Llithography, electroplating, and molding) and Deep Reactive Ion Etching (DRIE) techniques. Thermally actuated MEMS are used for achieving higher deflections with minimum forces and multiple voltage levels when compared to other actuation methods. Thermal micro actuators shows high repeatability and can be fabricated by IC-compatible manufacturing techniques. The MEMS thermal actuators are obtained from poly silicon which is a brittle material and becomes ductile after the transient temperature $(813 \mathrm{~K}, 933 \mathrm{~K})$ [5]. Thermal actuation has been widely applied in various MEMS devices. The thermal actuation includes number of operating principles such as bimetal effect, mechanical thermal expansion, thermal pneumatic and Shape Memory Alloy (SMA) effect. Mechanical properties were enhanced in microcantilevers made up of $\mathrm{Au} / \mathrm{Ti}$ bi-layered structure evaluated by micro-bending test. The highest yield stress at $1126 \mathrm{MPa}$ is observed in the Au/Ti bi-layered micro-cantilever composed of $63 \%$ gold [7]. Thermal actuation provides larger forces at the small scale when compared to electrostatic actuation. The added advantage of thermal actuation is ease with which it can be utilized to achieve a novel embedded Electro-Thermal-Compliant (ETC) actuation for MEMS. The principle of ETC actuation is based on the selective non-uniform Joule heating and the accompanying constrained thermal expansion $[8]$.

The performance of a thermal actuator is an influencing factor for the performance of a tunable capacitor. Thermal expansion provides larger forces and is easier to control compared with electrostatic forces. But a single-material actuator based solely on the thermal expansion of a beam will have a small deflection relative to the size of the actuator. If the actuator is made up of two different materials with differential expansion coefficients, the bimetallic or bimorph can be used for higher deflections [9]. Modeling of horizontal thermal actuator has begun by B Romanowicz, Ph Lerchand et al., and finite element method has been employed to thermal analysis the horizontal thermal actuator [10]. Electro thermally driven MEMS actuator was fabricated by surface micro machining process and the design optimization has been carried using finite element modeling [11]. Finite element modeling is used to predict thermo mechanical behavior of actuators under low to moderate voltage differences for determining the creep and fatigue failure. Results were validated and found that the maximum temperature occurs at the location where the high stresses were developed [12]. MEMS devices and structures can be actuated by injecting or removing heat. A change in temperature may result in mechanical displacement or force output, through thermal expansion, contraction, or phase change [13]. Finite element method simulations have been carried for large deflection behavior of a MEMS bimetallic thermally actuated membrane. The temperature distribution has been found using heat transfer analysis [14]. Bimetallic actuated membranes are used for providing high forces and large deformations. They require lower driving voltage and compatible with IC fabrication technology [15].

\section{Theoretical Modelling of Mems Bimetallic Strip Actuator}

A MEMS bimetallic strip actuator is used to convert a temperature change into mechanical displacement. The actuator consists of two different layered materials bonded together such that they expand at different rates as they are heated, 
Materials such Silicon $(\mathrm{Si})$ and Silicon dioxide $\left(\mathrm{SiO}_{2}\right)$ are used for this purpose. The bilayered micro actuators are used in micro tweezers actuated by thermal means. The bilayered micro actuator with distinct expansion coefficients make the strip curve either upward or downward when it is subjected to temperature rise or drop. A bilayered micro actuator subjected to a temperature change is shown in figure 1.

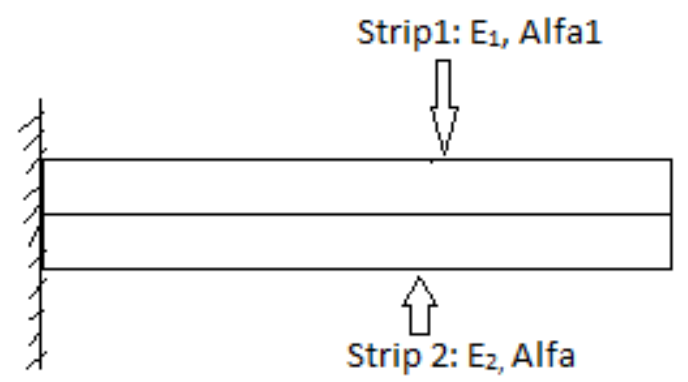

Figure 1: A Bilayered Micro Actuator Subjected to a Temperature Change.

In figure 1, strip1 can be an Oxidized silicon material bonded with trip2 (Silicon). $\mathrm{E}_{1}$ is the Young's modulus of the material 1 and $\alpha_{1}$ (Alfa1) is the co-efficient of thermal expansion of material 1. Similarly, $E_{2}$ is the Young's modulus of the material 2 and $\alpha_{2}$ (Alfa2) is the co- efficient of thermal expansion of material 2.

The interface force $\mathrm{F}$ is obtained by [6]

$\mathrm{F}=\frac{\left(\alpha_{2}-\alpha_{1}\right) \mathrm{T}}{\mathrm{s}} \frac{\mathrm{hb}}{\left(\frac{1}{\mathrm{E}_{1}}+\frac{1}{\mathrm{E}_{2}}\right)}$

The curvature of a bimetallic actuator strip is obtained by

$\rho=\frac{2 h}{3\left(\alpha_{2}-\alpha_{1}\right) T}$

$\mathrm{T}$ is the temperature change and $\mathrm{h}, \mathrm{b}$ are height and width of the combined strip

The movement of the free end of the bi material strip is given by

$\delta=\rho-\rho \cos \theta$

$\theta$ is the angle that corresponds to the arc in which the free end of the strip moves and is equal to $0.1574^{\circ}$. 


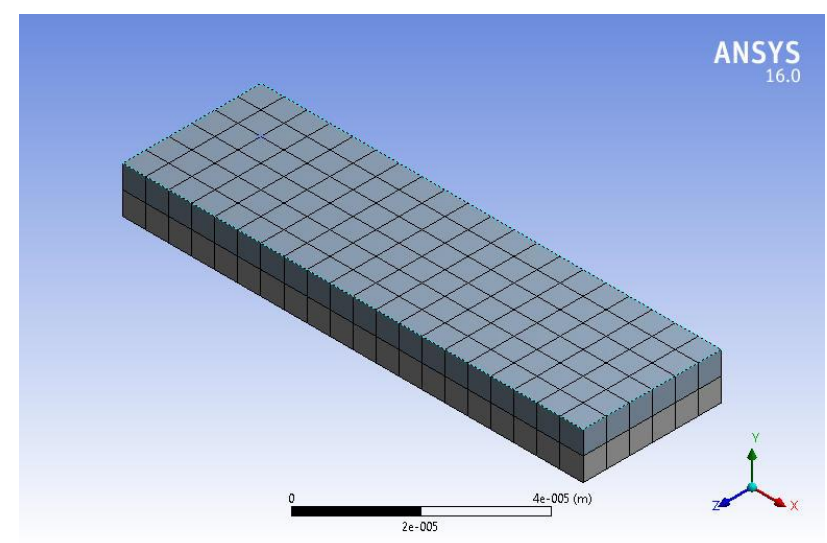

Figure 2: Mesh of the Model.

\section{FINITE ELEMENT MODELING}

The modeling of the MEMS bi metallic actuator was carried using ANSYS workbench, finite element software. The model consists of two layered materials i.e., a silicon dioxide layer of $5 \mu \mathrm{m}$ thickness bonded to silicon layer of same thickness. The length of the composite beam is $100 \mu \mathrm{m}$. simple meshing was used to discrete the model. Modeling was carried in two stages. First, steady state thermal analysis was carried with temperature boundary condition at the free end of the composite strip. The heat is transferred by convection from the other surfaces; therefore, convective boundary conditions with convective heat transfer coefficient and ambient temperature were applied. The model was solved with material properties of the two materials mentioned in table-1. The solution has been carried for steady state temperature boundary conditions. Later, the model was imported to static structural analysis. A fixed displacement boundary condition was imposed at the beginning end and the other end is made free. The mesh of the model is shown in figure 2 .

Table 1: Material Properties

\begin{tabular}{|l|c|c|}
\hline Material & Young's modulus (MPa) & $\begin{array}{c}\text { Thermal Expansion } \\
\text { Coefficient }^{\circ}{ }^{\circ} \mathbf{C}\end{array}$ \\
\hline $\mathrm{Sio}_{2}$ & 385.00 & $0.5 \times 10^{-6}$ \\
\hline $\mathrm{Si}$ & 190.00 & $2.33 \times 10^{-6}$ \\
\hline
\end{tabular}

\section{RESULTS AND DISCUSSIONS}

The temperature at the free end has changed from $22^{\circ} \mathrm{C}$ to $52^{\circ} \mathrm{C}$. The results were obtained in the form of deformation contours, stress-strain contours and data. The solution after steady state temperature analysis with initial steady state temperature boundary condition is shown in figure-3. A convective heat transfer coefficient of $100 \mathrm{w} / \mathrm{m}^{2}{ }^{\circ} \mathrm{C}$ with ambient temperature boundary condition has been applied on remaining surfaces after the model was imported to structural analysis. During structural analysis, the displacement boundary conditions erewas applied and the results were obtained. The total deformation of the actuator at $22{ }^{\circ} \mathrm{C}$ is shown in figure-4. Similarly the deformation at $52{ }^{\circ} \mathrm{C}$ is shown in figure-5. From the contours, it can be concluded that the curvature and deformation are increasing with increasing temperature. The deformation data plotted from temperature variation from $22{ }^{\circ} \mathrm{C}$ to $52{ }^{\circ} \mathrm{C}$ is shown in figure-6. It shows a linear variation between total deformation and temperature. From the results, it is also understood that the maximum deformation occurs at the middle and in between the two ends of the actuators due to bending stresses. The total deformation at $22{ }^{\circ} \mathrm{C}$ is $0.00028427 \mu \mathrm{m}$ and at $52{ }^{\circ} \mathrm{C}$ is $0.011159 \mu \mathrm{m}$. This shows that there is an increase in deformation with temperature. The results are compared with theoretical results and are in good agreement. For the clear visualization, the simplified models 
of total deformation without mesh and with undeformed model are shown in figures-7 and figure-8 respectively.

The contours of stresses generated due to differential expansion (thermal stresses) and at $22{ }^{\circ} \mathrm{C}$ and $52{ }^{\circ} \mathrm{C}$ are shown in figure -9 and figure- 10 respectively. The maximum equivalent stress at $22{ }^{\circ} \mathrm{C}$ is $0.0014934 \mathrm{MPa}$ and at $52{ }^{\circ} \mathrm{C}$ is $0.41881 \mathrm{MPa}$. Thus, the thermal stresses are more with the increase in temperature. The variation of normal stress and equivalent stresses with variation of temperature from $22{ }^{\circ} \mathrm{C}$ to $52{ }^{\circ} \mathrm{C}$ is shown as the graph in figures- 11 and figure- 12 respectively. The stresses are varying linearly with temperature as shown. The equivalent strain corresponding to equivalent stress at $22^{\circ} \mathrm{C}$ is shown in figure-13. Similarly, the equivalent strain corresponding to equivalent stress at $52{ }^{\circ} \mathrm{C}$ is shown in figure-14. The strain value is increased from $5.42 \times 10^{-6}$ to 0.00015229 . The variation of strain from $22^{\circ} \mathrm{C}$ to $52^{\circ} \mathrm{C}$ is shown as the plot in figure 15 .

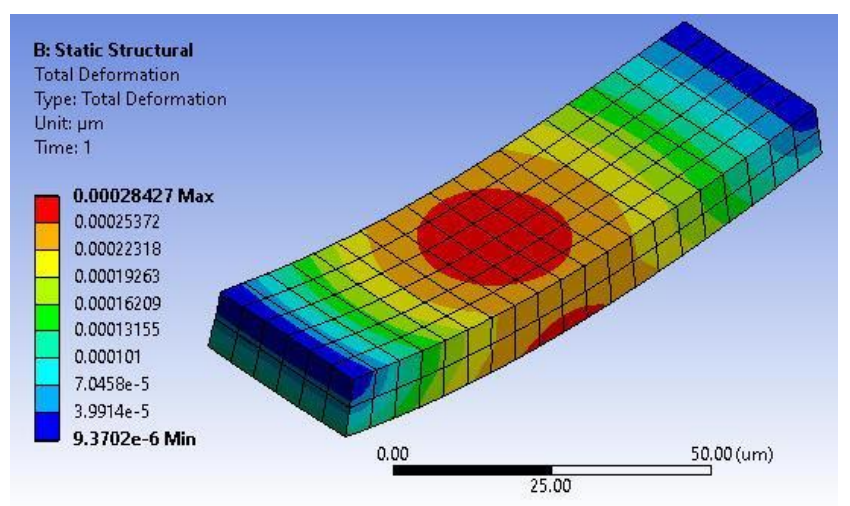

Figure 3: Steady State Temperature Boundary Condition at $22^{\circ} \mathrm{C}$.

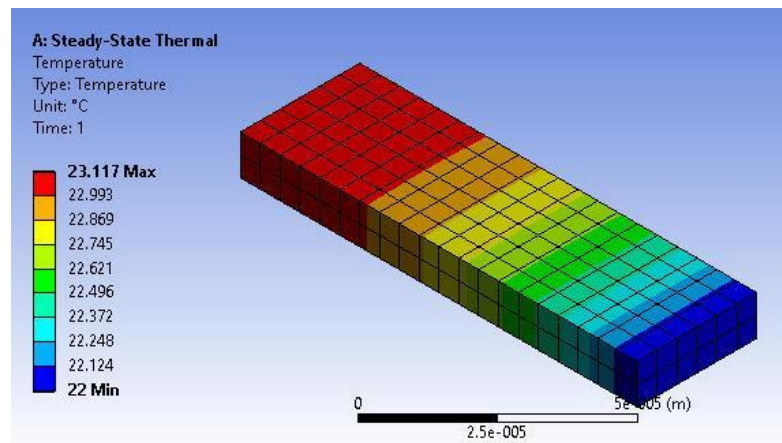

Figure 4: Total Deformation at $22^{\circ} \mathrm{C}$. 


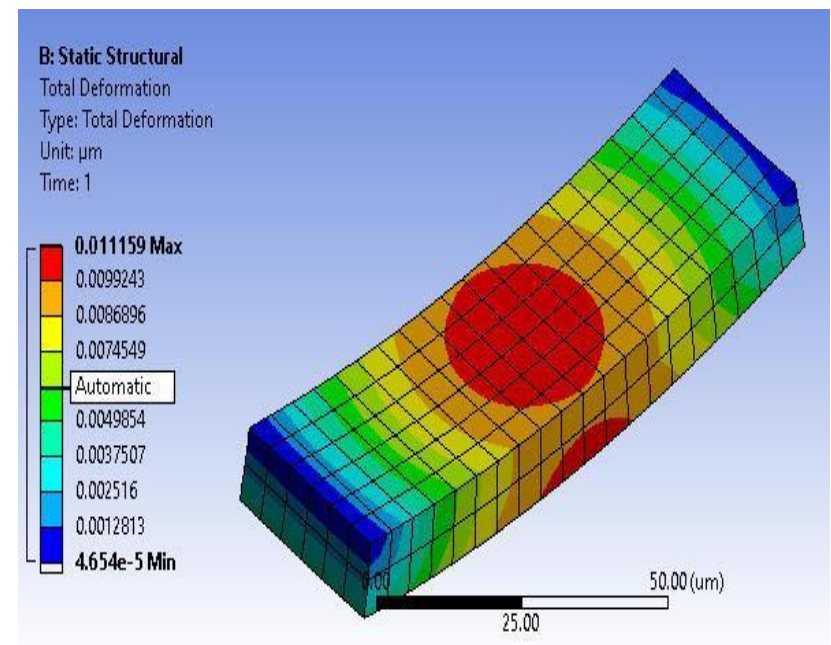

Figure 5: Total Deformation at $52^{\circ} \mathrm{C}$.

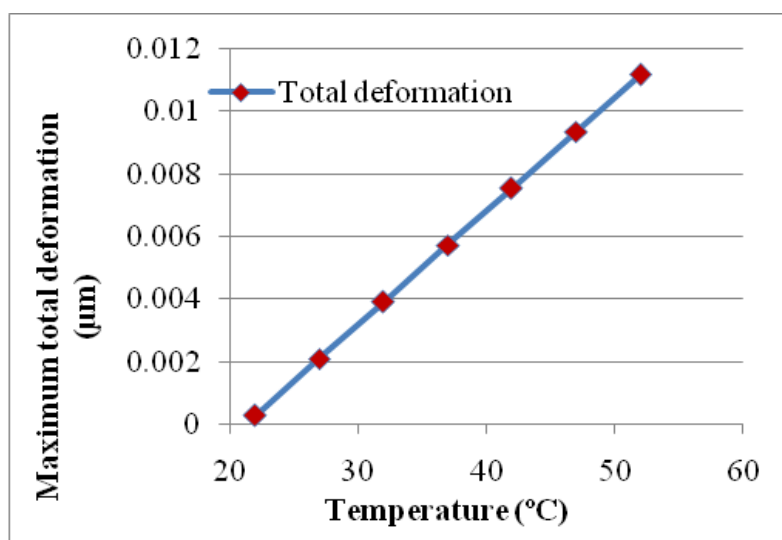

Figure 6: Plot of Total Deformation and Temperature.

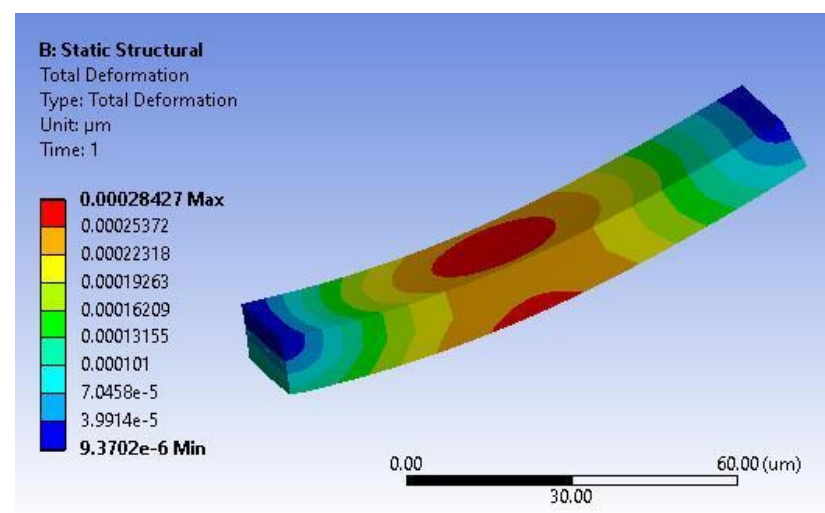

Figure 7: Total Deformation at $22^{\circ} \mathrm{C}$ (without mesh). 


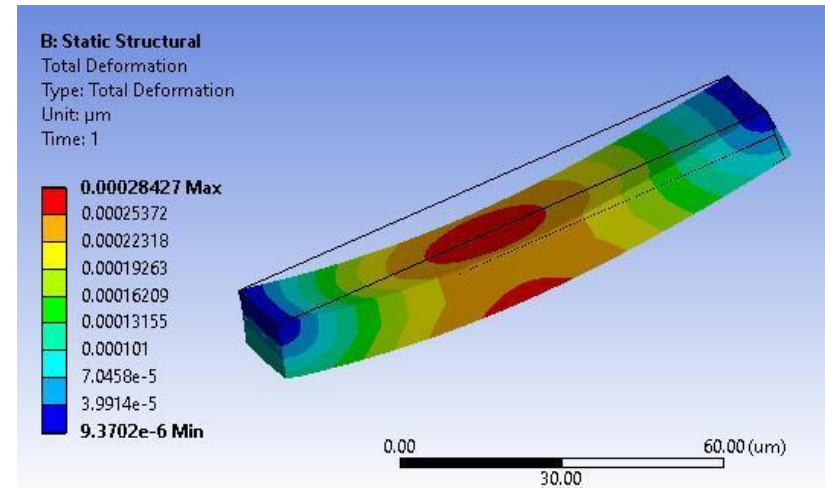

Figure 8: Total deformation at $22^{\circ} \mathrm{C}$ (Deformed and undeformed model).

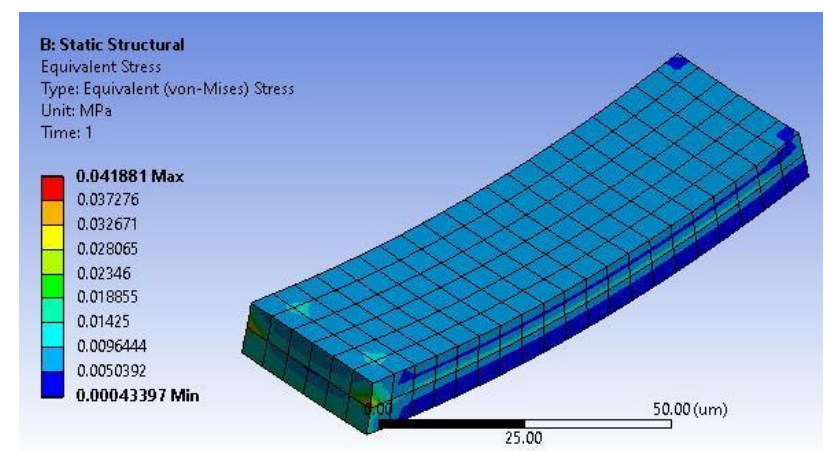

Figure 9: Equivalent stress at $22^{\circ} \mathrm{C}$.

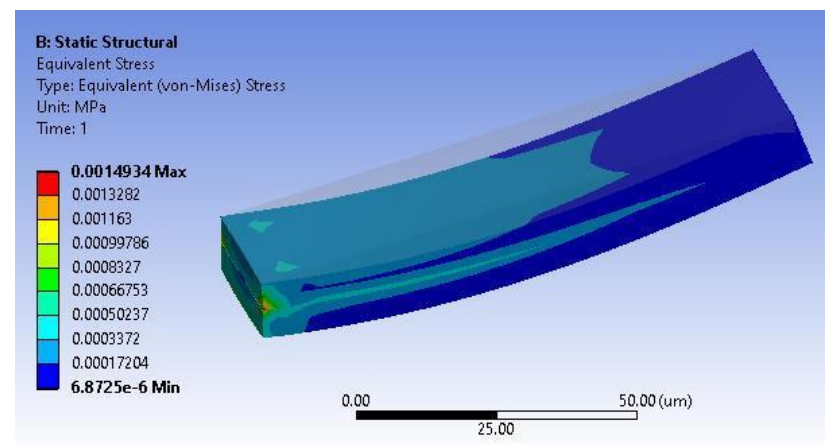

Figure 10: Equivalent stress at $52^{\circ} \mathrm{C}$. 


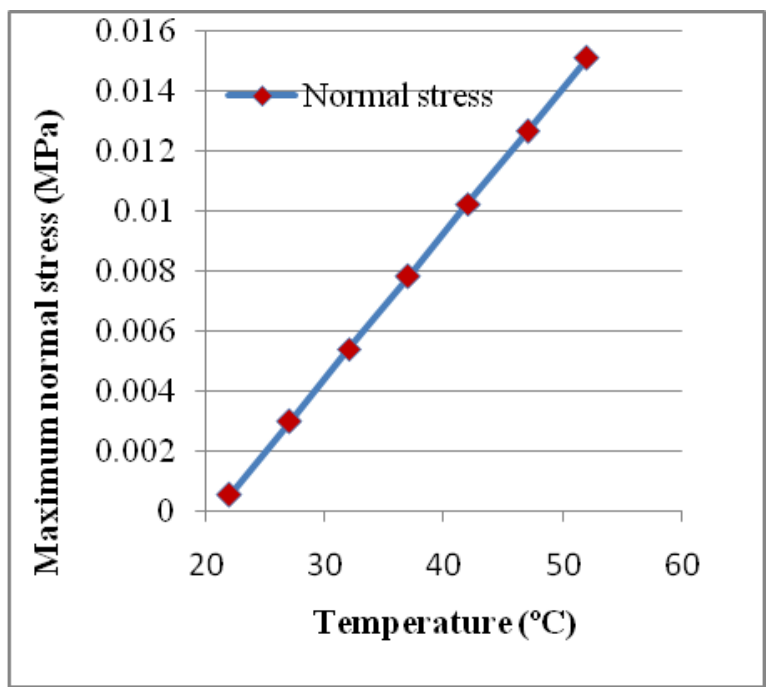

Figure 11: Normal Stress Variation with Temperature.

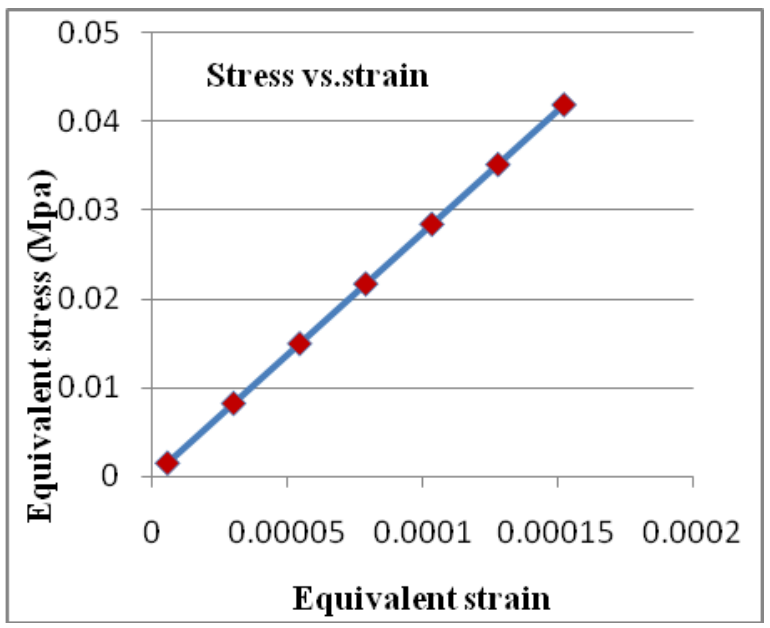

Figure 12: Equivalent Stress Variation with Temperature.

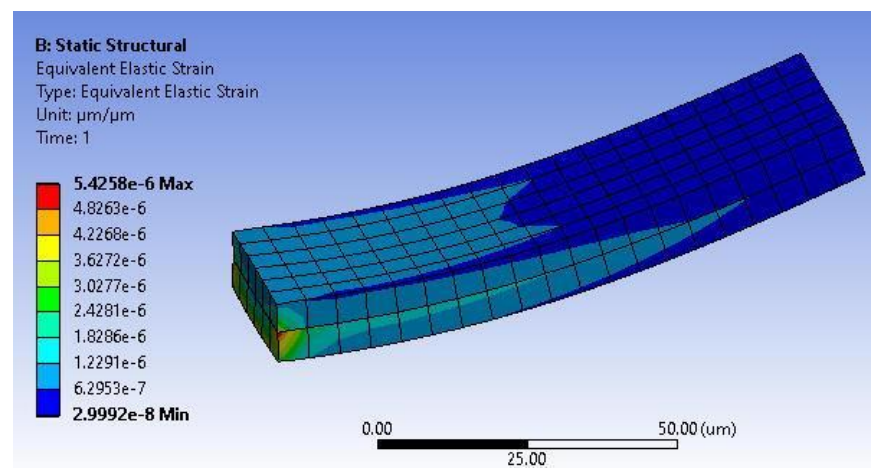

Figure 13: Equivalent strain at $22^{\circ} \mathrm{C}$. 


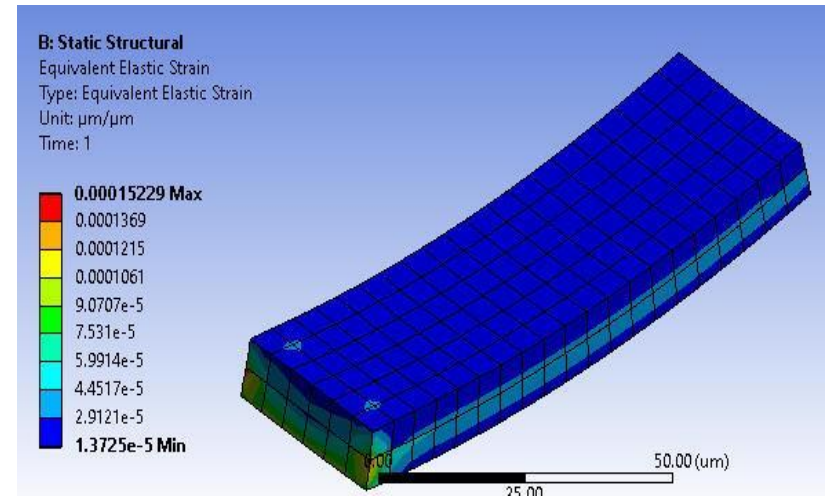

Figure 14: Equivalent Strain at $52^{\circ} \mathrm{C}$.

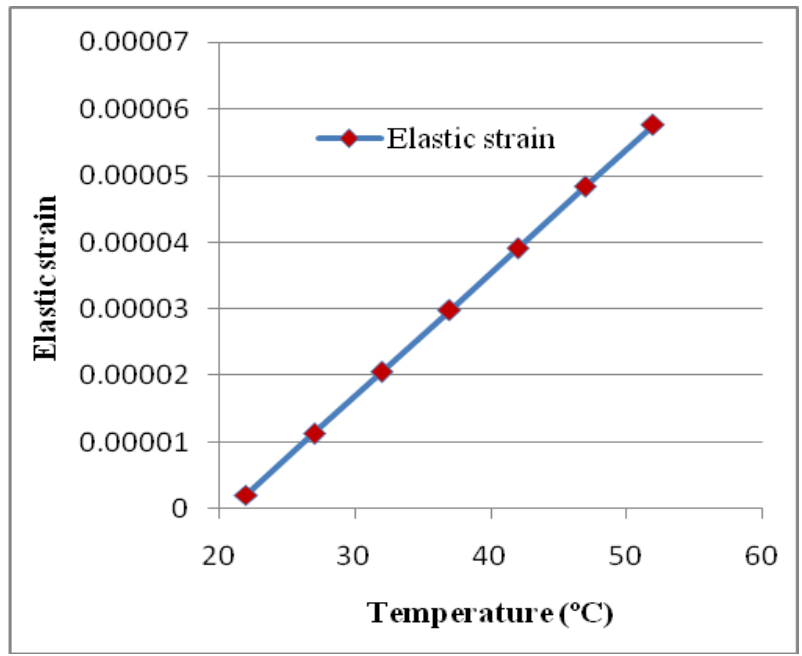

Figure 15: Variation of Strain with Temperature.

\section{CONCLUSIONS}

MEMS bi metallic actuator made up of silicon dioxide and silicon layered materials was modeled and simulated by finite element method. The thermal stress analysis was carried in two stages. In first stage, a steady state temperature distribution was carried and the model was imported to static structural analysis. Solution was carried for total deformation; stresses generated and strain with a temperature variation of $22^{\circ} \mathrm{C}$ to $52{ }^{\circ} \mathrm{C}$ at the free end. The results were obtained in the form of contours and graphs. The results of total deformation obtained by finite element modeling were compared with theoretical results and are in good agreement.

\section{REFERENCES}

1. H. Fujita, Future of actuators and microsystems, Sensors and Actuators A 56 (1996) 105-111.

2. Shahriar Kouravand, Design and modeling of some sensing and actuating mechanisms for MEMS applications, Applied Mathematical Modelling ,35 (2011) 5173-5181

3. Alissa Potekhina and Changhai Wang, Review of Electrothermal Actuators and Applications, Actuators 2019, 8, 69.

4. N.P. Mahalik, MEMS, TataMCGRAW-HILL, 2007

5. Viorel Ionescu, Numerical investigation of a MEMS thermal actuator performance by modifying its geometric dimensions, 
procedia manufacturing, 32(2019), 820-830.

6. Tai-ran Hsu, MEMS \& MICROSYSTEMS DESIGN and Manufacture, Tata MCGRAW-HILL, 2002

7. KenHashigata, Tso-Fu MarkChang et al, Strengthening of micro-cantilever by Au/Ti bi-layered structure evaluated by microbending test toward MEMS devices, Microelectronic Engineering, Volume 213, 2019, Pp.13-17

8. TimothyMoulton and G.K. Ananthasuresh, Micromechanical devices with embedded electro-thermal-compliant actuation, Sensors and Actuators A: Physical Volume 90, Issues 1-2, 2001, Pp. 38-48

9. John H. Comtois and Victor M. Bright, "Applications for surface-micromachined polysilicon thermal actuators and arrays," Sensors and actuators, vol. A (58), pp. 19-25, 1997

10. B Romanowicz Ph Lerch, C Kara Slimane and Ph Renaud, "Modelization and characterization of asymmetrical thermal micro-actuators, ”Journal of Micromechanics and Microengineering, vol. 6, pp. 134-137, 1996.

11. Roberto Venditti, Jacky S H Lee1, Yu Sun and Dongqing Li, An in-plane, bi-directional electrothermal MEMS actuator, Journal of Micromechanics and Microengineering, 16 (2006) 2067-2070.

12. Nasim Paryab AE Hamid Jahed AE Amir Khajepour, Creep and Fatigue Failure in Single- and Double Hot Arm MEMS Thermal Actuators, J Failure Analysis and Prevention, (2009) 9:159-170

13. Yang, X., C. Grosjean, and Y.-C.Tai, Design, fabrication, and testing of micromachined silicone rubber membrane valves. Journal of Microelectromechanical Systems, 1999. 8(4): p. 393-402.

14. $R$ Lefevre, A Salette et al, Numerical study of bimetallic actuated micro-membrane with large deformations, Journal of Micromechanics and Microengineering. 23 (2013) 015011.

15. Salette A, Lefevre R, et al, Thermal sensors cointegrated within a MEMS thermally actuated ultrathin membrane Journal of Micromechanics and Microengineering, 2012, 22, 065029

16. B. Navya Sri \& A. Chennakesava Reddy, "Formability of Elliptical SS304 Cups in Single Point Incremental Forming Process by Finite Element Method", IMPACT: International Journal of Research in Engineering \& Technology (IMPACT: IJRET), Vol. 4, Issue 11, pp. 9-16

17. Abdul Kadir Muhammad, Shingo Okamoto \& Jae Hoon Lee, "Comparison between the One Piezoelectric Actuator and the Two Ones on Vibration Control of a Flexible Two-Link Manipulator Using Finite Element Method", International Journal of Mechanical Engineering (IJME), Vol. 5, Issue 1, pp. 25-42

18. L. Umamaheswararao \& K. Mallikarjunarao, "Design and Analysis of Turbine Blade by using Fem”, International Journal of Mechanical Engineering (IJME), Vol. 4, Issue 1, pp. 1-8

19. J. Krishnaveni, G. Sowmya \& U. Sudhakar, "Thermal Analysis of Cylinder Head by using Finite Element Analysis", International Journal of Mechanical Engineering (IJME), Vol. 3, Issue 6, pp. 11-20 